\section{Perceptions of Physician Attire}

\section{TO THE EDITOR:}

Thanks to Dr Varnado-Sullivan and her colleagues for the article, "The Impact of Physician Demographic Characteristics on Perceptions of Their Attire" in the October 2019, issue of Family Medicine. ${ }^{1}$ Related to their findings, I have a personal anecdote other readers might enjoy. Early in my career, I looked a lot like Opie from The Andy Griffith Show and I found that dressing formally in a white coat, dress shirt, and tie helped me get past the "you're too young to be a doctor" assumptions by patients. I also liked all the pockets my white coat had for carrying the various tools and toys I thought I needed right at hand. However, once in practice, those same pockets led to serious consternation because I couldn't keep from catching them on the arms of the chairs in my office. One day, my wife, who was tired of sewing my pockets back on and tired of my pretending I couldn't do it myself, issued an ultimatum: "ditch that white coat and figure out something else." So I did.

I looked around our house and noticed my fishing vest had plenty of pockets that were too high to catch on the chairs. Because I thought a used fishing vest might be unseemly to my patients, I mail-ordered a brand new one. As Varnado-Sullivan and colleagues noted, I also perceived the importance of a name tag and had one professionally engraved with my name and role. Because I was concerned the vest might be too informal for some of my patients, I continued to wear a dress shirt and tie underneath. I was overwhelmed at how well my patients accepted the transformation. Working in a residency clinic, it is very important to me that I develop trust as efficiently as possible with many patients who are very different from me. Children, especially, are curious about my vest and much less intimidated than they were by my white coat. Older patients who suddenly realized they were talking with a fellow fisherman instead of just a doctor, began sharing their lives with me in a whole new way and, occasionally, put me on to some great fishing holes. Some of my colleagues still find my choice of attire quirky but I brushed them off years ago-I'm having too much fun wearing a fishing vest to work.

doi: 10.22454/FamMed.2020.667668

Scott E. Moser, MD

University of Kansas School of Medicine-Wichita Wichita, KS

\section{References}

1. Varnado-Sullivan P, Larzelere M, Solek K, et al. The impact of physician demographic characteristics on perceptions of their attire. Fam Med. 2019;51(9):737-741.

\section{Response to "Behavioral Science Rounds: Identifying and Addressing the Challenging Issues That Residents Face on a Family Medicine Inpatient Service"}

\section{TO THE EDITOR:}

George Saba, MD, et al's recent article regarding behavior science rounds ${ }^{1}$ highlighted the importance of providing a safe space for family medicine residents to reflect on the common challenges faced on a family medicine inpatient service. Discussion of these challenges will always remain a vital step in improving resident wellness. For resident wellness to move forward, however, medical education has an obligation to critically evaluate the current systems of care delivery that contribute to these challenges. By addressing these systemic factors, medical educators have the opportunity to improve patient care, enhance resident wellness, and decrease burnout.

An aspect of the article's described model for behavior science rounds includes "soliciting personal strategies for preventing and dealing with burnout." In response to the burnout crisis, many residency programs have implemented a wellness curriculum; these curricula tend to emphasize personal resilience. ${ }^{2}$ However, the systemic factors of the training environment are at least as important to the conservation of wellness, and deserve equal investment of time and energy by educational faculty and administrators. Since the 2003 
rollout of the duty-hour restriction, resident caseloads have not significantly decreased, leading to work compression. ${ }^{3}$ Nonphysician tasks such as scheduling, paperwork, and social work issues, are a major contributor to this work compression. The Institute of Medicine Committee "believes that the often high workload of residents and the compression of work into fewer hours are unrecognized contributors to risks for patient safety and resident well-being." 3 They concluded that the transfer of "scut" work to nonphysicians could allow residents to maintain their educational patient experience while still reducing duty hours. ${ }^{4}$

Reducing the amount of nonphysician task work is just one example of systemic change that supports resident wellness. Burnout is not a personal battle. If the medical community wants to accomplish wellness, then a team approach will be necessary to combat burnout. Medical educators need to not only emphasize personal resilience but also advocate for systems of care that support physician wellness. Family physicians, who excel at seeing the big picture, are in the perfect position for pioneering the change they would like to see in the structure of medical education.

doi: 10.22454/FamMed.2020.771589

Abby Huck, DO

Riverside Methodist Hospital Family Medicine Residency Program

Columbus, $\mathrm{OH}$

\section{References}

1. Saba GW, Villela T, Goldschmidt RH. Behavioral science rounds: identifying and addressing the challenging issues that residents face on a family medicine inpatient service. Fam Med. 2019;51(7):603-608.

2. Meeks LM, Ramsey J, Lyons M, Spencer AL, Lee WW. Wellness and work: mixed messages in residency training. J Gen Intern Med. 2019;34(7):1352-1355.

3. Chapter 3: Adapting the resident educational and work environment to duty hour limits. In: Institute of Medicine (US) Committee on Optimizing Graduate Medical Trainee (Resident) Hours and Work Schedule to Improve Patient Safety; Ulmer C, Miller Wolman D, Johns MME, editors. Resident Duty Hours: Enhancing Sleep, Supervision, and Safety. Washington, DC: National Academies Press; 2009 https://www.ncbi.nlm.nih.gov/books/NBK214944/. Accessed November 25, 2019.

4. Chapter 9: Resources to implement improvements for patient safety and resident training. In: Institute of Medicine (US) Committee on Optimizing Graduate Medical Trainee (Resident) Hours and Work Schedule to Improve Patient Safety; Ulmer C, Miller Wolman D, Johns MME, eds. Resident Duty Hours: Enhancing Sleep, Supervision, and Safety. Washington (DC): National Academies Press; 2009. https://www. ncbi.nlm.nih.gov/books/NBK214955/. Accessed November 25, 2019.

\section{Working Together to End our Physician Well-being Crisis}

\section{TO THE EDITOR:}

The article, "Making Sense of Family Medicine Resident Wellness Curricula: A Delphi Study of Content Experts" by Dr Lauren Penwell-Waines and colleagues published in the September 2019 issue of this journal does an excellent job of filling the literature gap with expert consensus of the most essential components of a residency wellness curriculum. ${ }^{1}$ The article ends with an important message that should not be overlooked: "Equipped with this information, [residency programs, faculty, and residents] can move tomorrow's physician workforce toward greater wellness." As a former associate program director at a family medicine residency program and current resident remediation specialist, the topics of wellness and well-being come up frequently. Each year I cofacilitate a statewide family medicine chief resident workshop with a wellness smallgroup session. Feedback from the residents is the same year after year: incorporating things like mindfulness education, yoga, and teambuilding activities are just adding to their to-do list and are not actually helpful. Furthermore, residents note that their own faculty are burnt out and do not role model wellness as leaders. Table 2 of the article appears to agree: faculty role modeling wellness behaviors was thought to be essential to well-being action plans. On the other hand, things that scored much lower included structured reflection activities and nurturing and enhancing interprofessional relationships.

We do not equip our residents with the proper tools needed to proactively address their individual struggles. This is borne out in the data: nearly half of US resident physicians experience professional burnout during training. ${ }^{2}$ While reading the article by Penwell-Waines and colleagues, I gained a new perspective on a program in our residency designed to proactively identify and help residents struggling early in their training in order to prevent them from struggling to meet the ACMGE competencies later on. Customized competency-based assessments coupled with individualized learning plans (ILPs) were implemented at the beginning of internship year. The plans were assessed and evolved over time as residents' knowledge, skills, and behaviors improved throughout their training. 
In retrospect, I am astonished that we did not view this as a wellness program in addition to an academic intervention. The intervention embodied key elements of wellness: encouraging self-disclosure of struggles; selfassessment; setting and monitoring achievement of personal and professional goals per an ILP; and mentorship and role-modeling by faculty. It also meets the new ACGME requirement for use of ILPs and the subcompetency that each resident should be able to "recognize and develop a plan for one's own personal and professional well-being."3

While we did not formally study the effects of our program on resident well-being, feedback from our residents was positive overall. In addition, a literature search identified only one similar program where an integrated advisory and assessment pilot program was implemented with reassuring results on resident well-being. ${ }^{4} \mathrm{I}$ believe the use of resident assessments early in training coupled with ILPs and skilled mentoring may not only address residents' academic difficulties, but can also help pave the path toward increasing residents' sense of wellbeing during their training and beyond.

This is a clear call to action to promote the personal and professional development and well-being of trainees. I challenge my peers to be the driving force for a proactive, innovative, and customized approach to residency wellness curricula. We must arm this next generation of physicians with the tools needed to circumvent the physician well-being crisis. doi: 10.22454/FamMed.2020.663176

Nida S. Awadallah, MD, FAAFP

University of Colorado School of Medicine Aurora, $\mathrm{CO}$

\section{References}

1. Penwell-Waines L, Runyan C, Kolobova I, et al. Making sense of family medicine resident wellness curricula: a delphi study of content experts. Fam Med. 2019;51(8):670-676.

2. Dyrbye LN, Burke SE, Hardeman RR, et al. Association of clinical specialty with symptoms of burnout and career choice regret among US resident physicians. JAMA. 2018;320(11):1114-1130.

3. Accreditation Council for Graduate Medical Education. ACGME Common Program Requirements, Effective July 1 , 2019. https://www.acgme.org/Portals/0/PFAssets/ProgramRequirements/CPRResidency2019-TCC.pdf. Accessed October 15, 2019.

4. Foster E, Biery N, Dostal J, Larson D. RAFT (Resident Assessment Facilitation Team): supporting resident well-being through an integrated advising and assessment process. Fam Med. 2012;44(10):731-734.

\section{Authors' Reply to “Working Together to Heal Our Physician Well-Being Crisis"}

\section{TO THE EDITOR:}

We appreciate Dr Awadallah's comments on our paper and her commitment to promoting resident well-being. The innovative intervention she describes at her program is consistent with several of the most highly-rated elements of a wellness curriculum in our study: to begin conversations about wellness early and continue them throughout residency training, integrate these conversations into the advising and mentoring process, and measure resident well-being through qualitative methods. It is possible that the individual learning plan (ILP) meetings she describes also could incorporate several other essential elements to promote well-being by serving as a time to connect with a mentor and facilitating confidential disclosure for burnout and impairment. ${ }^{1}$ We encourage her and other program leaders to consider how they might be intentional about incorporating the essential elements into their existing wellness initiatives. We also encourage individuals responsible for wellness curricula to advocate for protected time and a budget to implement wellness initiatives, a crucial factor in getting these programs off the ground. ${ }^{2}$

Regarding other elements of a wellness curriculum, Dr Awadallah points out that many residents do not view mindfulness training and team-building as very helpful and even find them onerous. Though these elements were not as highly rated as those previously mentioned, they were still considered by the expert panel to be essential to a wellness curriculum and have been shown to have benefits for resilience. ${ }^{1,3}$ The tension between resident and family medicine educator opinions underscores the importance of delivery of wellness interventions (eg, creating time and space for them, offering options that can be tailored to individual resident needs and the culture/context of the program), so that residents are not left feeling burdened with one more thing to do. This discrepancy also highlights the need to advance the literature on resident wellness by studying the relative effectiveness of the components of a wellness curriculum on wellbeing outcomes (eg, career satisfaction, resilience) and academic/professional performance.

Finally, we echo Dr Awadallah's call to action for residency programs to develop and evaluate innovative ways to equip the "next 
generation of physicians with the tools needed to circumvent the physician well-being crisis." By sharing best practices, together we can make a difference.

doi: 10.22454/FamMed.2020.916601

Lauren Penwell-Waines, PhD

Novant Health Family Medicine Residency Program Cornelius, NC

Jill Schneiderhan, MD

University of Michigan Medical School

Ann Arbor, Ml

Valerie Ross, MS

University of Washington

Seattle, WA

Aaron Grace, PsyD

Medical College of Wisconsin

Waukesha, WI

Katherine Buck, PhD, LMFT

John Peter Smith Family Medicine Residency

Ft Worth, TX

Julie Brennan, PhD, RD, LD

University of Toledo Medical Center

Maumee, $\mathrm{OH}$

\section{References}

1. Penwell-Waines L, Runyan C, Kolobova I, et al. Making sense of family medicine resident wellness curricula: A Delphi study of content experts. Fam Med. 2019;51(8):670-676.

2. Penwell-Waines L, Cronholm P, Brennan J, et al. Getting it Off the Ground - Key Factors Associated with Implementation of Wellness Programs: A CERA Study. Fam Med. In press.

3. Brennan J, McGrady A. Designing and implementing a resiliency program for family medicine residents. Int J Psychiatry Med. 2015;50(1):104-114 